\title{
Exploring Omani EFL Students' Written Linguistic Accuracy Development in Disciplinary Contexts
}

\author{
BAKHTIAR NAGHDIPOUR \\ Faculty of Language Studies, \\ Sohar University, Oman \\ BNaghdipour@su.edu.om \\ KAIS AMIR KADHIM \\ Faculty of Language Studies \\ Sohar University, Oman
}

\begin{abstract}
It is generally assumed that undergraduate students' L2 written linguistic accuracy develops naturally in academic contexts as they engage in disciplinary content. To provide evidence of linguistic accuracy development in EFL writing, this study examines university students' ability to identify and correct linguistic errors (spelling, grammar and punctuation) in their writing and the mediational means or resources they consult to deal with such errors in disciplinary contexts. A mixed-method approach was employed to collect quantitative and qualitative data from undergraduate students $(N=60)$ who took a first-year essay writing course at a major university in Oman. In addition, Fourth-year, third-year, and second-year students majoring in social sciences proofread their essays written for the course final exam in the first semester of their studies. All participants were also interviewed to obtain insights into the likely resources and strategies they used to improve the linguistic accuracy of their writing. The results revealed that the length of the study was not a key factor affecting students' written linguistic accuracy development, as fourth-year students significantly outperformed their counterparts only in identifying and fixing the surface-level spelling and punctuation errors. Furthermore, the students' use of learning strategies and resources varied depending on individual factors such as future academic goals and career prospects. The paper concludes with a discussion of pedagogical implications and future research directions in EFL contexts.
\end{abstract}

Keywords: EFL writing; learning-to-write; linguistic accuracy; Oman; writing-to-learn

\section{INTRODUCTION}

Academic degree programmes give a great deal of weight to written exams, assignments, and projects. Hyland (2013b, p. 53) believes that "universities are ABOUT writing" and "it is central to constructing knowledge, educating students and negotiating a professional academic career". In producing and sharing this negotiated knowledge, linguistically correct written communication plays a vital role. Although disciplinary faculty expect students to compose linguistically correct texts, they might assume that such an ability develops naturally while students move through academic content and discourse over time. As a result, they may devote sufficient time and energy addressing other areas of writing development such as organisation, argument and rhetoric at the expense of attending to language-related concerns (Hyland, 2013a). Proponents of the writing-to-learn perspective to teaching writing (e.g., Harklau, 2002; Manchón, 2011) argue for the potential of exposing students to disciplinary content to better help them notice language forms and, as a result, improve their written linguistic knowledge. Hyland (2007), for example, notes that students' engagement in meaningful disciplinary content could provide them with opportunities to notice the contextualised use of grammar and the way it works in context. From this perspective, written linguistic accuracy develops effortlessly as students interact with disciplinary content and discourse - through reading-towrite and writing-to-read activities, sitting for written exams and quizzes and submitting written projects and assignments. To put this into perspective, the potential of disciplinary 
engagement to develop different aspects of student L2 writing has been recently investigated in different settings (e.g., Knoch et al., 2014; Knoch et al., 2015; Lee, 2020; Oppenheimer et al., 2017). Such research, however, remains scarce in EFL contexts where college and university students need to spend more time attending to language-related issues in their written work due to insufficient exposure to linguistic input and sources of scaffolding or feedback (Naghdipour, 2021).

The purpose of the current study is to investigate the extent to which engagement in disciplinary content and discourse develops undergraduate students' written linguistic accuracy. In other words, the study intends to examine the effect of the writing-to-learn perspective, or the use of writing to create and disseminate knowledge (Manchón, 2011), on students' written linguistic accuracy development. It also explores the likely resources, or strategies students consult to detect and fix linguistic errors in writing across the curriculum. Written linguistic accuracy development is operationally defined as students' ability to identify and correct three prominent language-related errors (i.e., spelling, grammar and punctuation) in their texts. It is hoping that the findings inform faculty teachers in these and similar EFL contexts of designing more effective pedagogical spaces that would offer students opportunities to engage in various learning and feedback resources and strategies to better address linguistic issues in their writing. The findings can also contribute to the ongoing debates on the effectiveness of writing-to-learn pedagogical approaches and practices in EFL writing.

\section{LITERATURE REVIEW}

\section{LINGUISTIC ACCURACY}

Writing pedagogy has witnessed many developments over the second half of the $20^{\text {th }}$ century, moving from product-based to process-based, genre-based, eclectic approaches and writing across the curriculum, to name a few, depicting a spectrum of teaching approaches that range from those focusing on form at one end to those emphasising meaning at the other. The distance from pure linguistic product-based approaches to teaching writing in recent decades is best reflected in the learning-to-write vs writing-to-learn dichotomy (e.g., Ferris \& Hedgcock, 2013; Harklau, 2002; Manchón, 2011), with the latter receiving more attention as writing is gaining broader recognition in the process of knowledge construction and sharing in disciplinary contexts (Bawarshi \& Reiff, 2010; Bazerman, 2009; Hyland, 2007; Manchón, 2011). Although accuracy development studies in writing classes and programmes have traditionally focused on corrective feedback practices (Bitchener \& Knoch, 2010; Ferris, 2010; Ferris et al., 2013; Nusrat et al., 2019; Storch, 2010), engaging students in disciplinary content has also been suggested as one strategy to scaffold their written linguistic accuracy development in addition to building their socioliterature repertoire. However, research investigating the role of disciplinary acculturation through adhering to writing-to-learn perspectives in helping students improve their linguistic accuracy in writing is still in its infancy (Knoch et al., 2014; Knoch et al., 2015).

\section{ACCURACY DEVELOPMENT IN L2 WRITING CLASSES}

Research investigating linguistic accuracy development in L2 writing classes is predominantly concerned with studies on written corrective feedback (WCF) or grammar correction, as the purpose of any WCF intervention is to improve linguistic accuracy (Ferris, 2010; Storch, 2010). Advocates of corrective feedback strategies cite several second language acquisition (SLA) 
theories to address linguistic issues or errors in students' writing. Chief amongst them is the noticing hypothesis (Schmidt, 2001) that considers negative evidence or erroneous cases of the target language essential for learning. As a focus-on-form pedagogical intervention, WCF has the potential to draw language learners' attention to form in the context of a communicative act (Ellis, 2005). When reviewing and reflecting on the feedback or input received, learners have the opportunities to notice the gaps in their interlanguage and take action to fill them by consulting the mediating learning sources and resources at their disposal. While offering input in the form of feedback on writers' errors might be necessary, it is not sufficient for writing development. To give credit to students' engagement with input, Swain (2005) proposed the output hypothesis suggesting that language learners need to have opportunities to interact with others in the target language to test their hypotheses or notice the gaps in their linguistic knowledge. Swain (2005) believes that when learners notice gaps in their interlanguage, they move from fluency to linguistic accuracy and may modify or fill in the noticed gaps in their knowledge of language. Similarly, skill acquisition theory (DeKeyser, 2007) supports the incorporation of corrective feedback practices in L2 writing classes. According to this theory, the practice of fixing errors and bridging gaps in learner interlanguage can lead to greater automatisation in the use of language. In other words, students take their time to practise various features of the target language to the point of making their explicit knowledge implicit or consolidated (DeKeyser, 2007).

Although research on the effectiveness of WCF has yielded mixed results, there is a strong consensus that such feedback has the potential to boost student linguistic knowledge (e.g., Bitchener \& Knoch, 2010; Ferris et al., 2013; Mansourizadeh \& Abdullah, 2014; Nusrat et al., 2019; Van Beuningen et al., 2012). Most teachers also advocate corrective feedback in their writing classes to support accountability in educational programmes, as students, parents, and authorities expect or view it as an effective pedagogical practice (Chen, Nassaji, \& Liu, 2016; Lee, 2009). However, despite strong evidence in favour of WCF provision in writing classes and programmes, most of these studies (e.g., Evans et al., 2010; Hyland \& Hyland, 2006) have acknowledged that WCF is a complex pedagogical practice whose successful implementation in writing classes is mediated by a range of different factors. Some of these factors include error type and treatability (Ferris, 1999), learners' developmental readiness (Pienemann, 1989), their L2 proficiency level (Hyland \& Hyland, 2006) and their motivation to apply the received feedback to minimise the likelihood of resurfacing errors in the subsequent performance (Waller \& Papi, 2017).

To diversify written corrective feedback practices and supplement teacher response with more social and student-centred feedback activities, alternative strategies such as peercorrection and self-correction have been introduced in different learning contexts (e.g., Abadikhah \& Yasami, 2014; Ferris, 2006; Mawlawi Diab, 2016; Shen et al., 2020). Teachers usually train students to help them better identify and correct errors in their own or peers' work to enhance the effectiveness of such alternative practices. When trained, peers were found to offer more constructive feedback (Rollinson, 2005) and exhibit greater learning autonomy (Shen et al., 2020). At the same time, L2 pedagogical practices such as content-based approaches have appeared on the scene, which claim that students can develop their written linguistic accuracy while navigating disciplinary content and discourse (Bawarshi \& Reiff, 2010; Bazerman, 2009; Hyland, 2007; Manchón, 2011).

\section{ACCURACY DEVELOPMENT IN WRITING ACROSS THE CURRICULUM}

Researches have also focused on the impact of the time students spend engaging with disciplinary content and discourse on their linguistic accuracy development (Knoch et al., 2014; Knoch et al., 2015). However, most of these studies have been concerned with short- 
term changes, addressed study abroad or graduate writing programmes, carried out in ESL contexts or investigated other aspects of writing, not necessarily linguistic accuracy development. For example, in a study abroad programme over a three-month summer course in English for academic purposes, Shaw and Liu (1998) found a minor change in students' linguistic accuracy scores than other aspects of L2 writing development. In another study, Storch and Hill (2008), who studied a group of international students' English proficiency, reported that students improved their writing skills after one semester but had the smallest gain in grammar. The authors argued that grammatical accuracy does not depend much on students' exposure to the target language but on the amount of feedback they receive and the emphasis on producing the accurate language. Later, Storch (2009) conducted a study on international students' writing development at an Australian university and found that students improved the quality of their ideas or the content of their writing after a semester. However, no changes were observed in their linguistic accuracy.

Furthermore, Knoch et al. (2014) examined a group of undergraduate students' L2 writing proficiency following a one-year degree study in Australia and reported that while students' writing fluency improved over time, no gains were recorded in their writing accuracy. Later, Knoch et al. (2015) investigated a group of undergraduate students' L2 writing proficiency following a three-year degree study and came up with the same findings. Students' engagement with disciplinary content may not necessarily affect their linguistic accuracy because faculty at disciplinary contexts, as Hyland (2013a) notes, direct their feedback mostly at addressing issues related to the content and discourse rather than those concerned with linguistic accuracy.

More recently, Oppenheimer et al. (2017) have examined undergraduate students' writing performance as part of a nine-year longitudinal study at a university in the US. Analysing students' writing samples revealed reliable gain scores in their writing performance over time, with women showing more significant improvement than men and students majoring in social sciences and humanities performing better than those majoring in natural sciences and engineering. However, while this study highlighted the role of outcome assessment in undergraduates' writing development, it did not focus on writing accuracy per se. Lee (2020) has also employed a mixed-method design to track two Korean university students' improvement of English writing over 12 months. The participants composed and submitted the first and second drafts of an assigned essay every month. The analysis of students' overall scores, errors and measures of writing fluency and grammatical complexity showed improvement in their writing over time. However, the study was more concerned with the impact of feedback generated by an automated writing evaluation tool on students' writing development than with the effect of disciplinary socialisation on students' written linguistic accuracy.

Given that research investigating students' linguistic accuracy development in writing across the curriculum is still scarce in EFL contexts (Lee, 2020), this study seeks to examine the extent to which Omani university students' linguistic accuracy develops as the result of disciplinary socialisation or being exposed to a writing-to-learn perspective to L2 writing development. It also intends to explore the likely resources and strategies students consult to produce linguistically correct texts in degree programmes.

\section{THE STUDY}

The current study aims to investigate the extent to which EFL students' written linguistic accuracy - represented here by an ability to identify and fix errors of spelling, grammar and punctuation - develops as they engage with disciplinary content and the sources, resources, 
strategies and practices that might help them to do so. In particular, the design of this study is guided by the following research questions:

1. To what extent can EFL undergraduates identify and fix their written linguistic errors in disciplinary contexts?

2. What strategies and resources do EFL undergraduates use to fix their written linguistic errors in disciplinary contexts?

A mixed-method approach to data collection and analysis was adopted to gather and analyse quantitative and qualitative data and information. Quantitative data were used to respond to the first research question addressing the impact of students' disciplinary acculturation on their writing accuracy development. However, the qualitative data from interviews were employed to answer the second research question, which was concerned with exploring students' use of learning resources and strategies to minimise linguistic errors in their writing as they navigated the requirements of writing across the curriculum.

\section{PARTICIPANTS}

Participants of this study were 60 undergraduate students (20 second-year, 20 third-year and 20 fourth-year) majoring in social sciences such as English, business and psychology. Firstyear students were excluded as the study focused on the impact of time (at least one year) students engage in disciplinary content on their linguistic accuracy development in writing. The participants were studying at an international university in Oman, where an overwhelming majority of colleges and universities adhere to an English as the medium of instruction policy (Naghdipour, 2021). To enter their degree programmes, students need to provide evidence of English language proficiency (e.g., IELTS score of 5). Those who cannot fulfil this requirement have to attend a General Foundation Programme (GFP) for up to three or four semesters to build their knowledge of general English to prepare for disciplinary studies (Naghdipour, 2021). All participants were female, as an overwhelming majority of students majoring in social sciences at this institution, following the trend across the country, were female, and the very few male students did not volunteer to participate in the study. Thus, gender was not regarded as a variable because the sample, to a large extent, represents the population of students.

Given that all the participating students majored in social sciences, the relationship between students' discipline or field of study and their writing accuracy development was not investigated. All participants took an essay writing course with the lead researcher during the first semester of their studies. The course aimed to develop students' skill of writing 250- to 300 -word long essays in different rhetorical modes. The participants were full-time Arabic speaking Omani nationals with an average age of 19.76 years. All participants reported attending Arabic-medium high schools where English is taught as a subject, and teachers use traditional pedagogical approaches which "place grammar drills and vocabulary memorisation above the development of English communicative proficiency" (Al-Mahrooqi \& Denman, 2018 , p. 2). The students volunteered and agreed to participate in the study in response to a request sent via email. They read and signed a consent form before starting the data collection process, stipulating that their identity would never be disclosed and their responses would be used for research purposes only. Students in each group received one session ( 90 minutes) of free consultation and tutoring on professional writing as an incentive for their participation. 


\section{DATA COLLECTION}

Background Questionnaire: Students filled out a background questionnaire to obtain their demographic information such as the field of study, year of study, CGPA, and age. Descriptive analysis was carried out to analyse the students' responses to the items on the questionnaire, and the results were reported to provide background information on the participants and help discuss or interpret the findings.

Error-correction Task: To answer the first research question, students were requested to proofread their final exam essays written for the writing course taken in the first semester of their studies. Since the text was written for the course final exam carrying $40 \%$ of the assessment weightage, it was a controlled assessment method of linguistic accuracy with high ecological validity (Boggs, 2019) and pedagogical credibility (Bruton, 2009). The participating students were selected from those in the middle of the continuum of writing proficiency, i.e., neither the high achievers (those who scored A) nor the very low achievers (those who scored D) were selected; only students who obtained B and C grades were allowed to participate. Most of the high achievers had an excellent command of English and, as a result, did not have many linguistic errors in their writing. On the other hand, low achievers had a CGPA score of less than two on a scale of four and did not usually go through different academic years as they had to take fewer courses every semester and repeat courses with F \& D marks to boost their CGPA. As most of them wrote within this range, errors were taken from reading 200 words of students' essays. Those who wrote less were excluded to ensure consistency. The first group of students wrote their essays in Fall 2016, the second group in Fall 2017, and the third group in Fall 2018. All groups then proofread their work in Fall 2019. Students were asked to read their essays carefully, identify and correct the likely linguistic errors in spelling, grammar, and punctuation, as the most common, familiar aspects of linguistic accuracy. Students were given the instructions verbally and completed the task individually at the comfort of an empty classroom (used only by graduate students in the evenings) and were given from 10 to 15 minutes to read their essays twice and correct their errors, but they were not allowed to consult any resources. The participating students also expressed their excitement seeing their paper after some time which further motivated them to concentrate on the task.

Semi-structured Interviews: To answer the second research question, each student was interviewed by the teacher (lead researcher) after completing the error-correction task. These semi-structured interviews were conducted in English, taking approximately between 10 and 15 minutes each. Students were recorded digitally with their permission to attend the interview process fully. The interview protocol was prepared based on a literature search and included six main questions with several follow-up inquiries to further probe students' experiences of dealing with linguistic errors in their writing. The questions mainly focused on the writing tasks and projects students encountered, feedback received, and strategies used to reduce linguistic errors in their writing, along with explanations of the likely improvement in their written linguistic accuracy over time or lack thereof (see Appendix).

\section{DATA ANALYSIS}

Analysis of the collected data was carried out manually and included counting the spelling, grammar, and punctuation errors students identified and fixed, identified but were not able to fix, and the wrong attempts or those misidentified as errors (Table 1). While linguistic accuracy has been conceptualised and defined in many different ways (see Polio, 1997 and Polio \& Shea, 2014, for a review), accuracy measure in this study was calculated, following Chandler (2003) and Naghdipour and Koc (2015), as the raw number of linguistic errors students successfully identified and fixed in 200 words. Repetition of an error was not counted as another error, and 
this was mentioned in the given instructions on the error-correction task. The errors were counted and double-checked by both researchers to ensure reliability further. The inconsistencies in counting the errors were discussed and finalised in a meeting. It is worth noting that only students' proofreading of their essays was the focus of the study, and the errors and issues related to other areas (e.g., content and organisation) were not considered. The descriptive analysis was carried out separately for each group and each different aspect of writing accuracy. Then, One-Way ANOVA was conducted to examine the between-group differences in three different categories.

TABLE 1. Extracts on error correction attempts from students' essays

\begin{tabular}{ll}
\hline Error attempt & Example \\
\hline Identified \& fixed & Original: Universities prapare* students for work. \\
(Spelling) & Edited: Universities prepare students for work. \\
Identified but not fixed & Original: ... I agree for* homework helps students a lot. \\
(Grammar) & Edited: ... I agree with* homework helps students a lot. \\
Wrong attempt & Original: We work in groups to do our projects, so we can learn more. \\
(Punctuation) & Edited: We work in groups to do our projects;* so we can learn more. \\
\hline
\end{tabular}

In addition, the data from the interviews were transcribed and filed. The scripts were then subjected to thematic analysis to identify the recurring themes and patterns and figure out their interrelationships. Finally, the lead researcher read students' responses to each interview question several times to extract from the data the most frequent or common strategies and resources they consulted to tackle linguistic errors in their writing as they moved from one academic semester to another. These resources were mainly the artefacts (e.g., technological tools) and human agents (e.g., peers) students consulted to improve the linguistic accuracy of their written work. The strategies mentioned by more than two students were counted; others were excluded on the grounds of being idiosyncratic. In other words, the key to taking a strategy into account was its repetition by at least three students. When the most common strategies and resources were identified, students' comments were edited to ensure clarity and reported to support the emerging themes as well as findings of the study.

\section{RESULTS}

In response to the first research question, a one-way between-subjects ANOVA was run to compare the students' scores on their attempts to identify and correct spelling, grammar, and punctuation errors in their essays. Table 2 reports the descriptive analysis results, while Table 3 displays the results of a one-way ANOVA of students' error identification and correction attempts in spelling. The results indicate that differences between the means of students' scores were significant at the $\mathrm{p}<.05$ level for the first attempt (identified \& fixed) $[\mathrm{F}(2,57)=4.9, \mathrm{p}$ $=.012]$ only. This difference was explicitly manifest in the performance of the fourth-year students who outperformed their counterparts in detecting and fixing misspelt words in their essays.

TABLE 2. Descriptive analysis of students' gain scores in spelling

\begin{tabular}{lllll}
\hline Treatments & $\mathrm{n}$ & Error correction attempts & $\mathrm{M}$ & $\mathrm{SD}$ \\
\hline Fourth-year students & \multirow{2}{*}{20} & Identified \& fixed & 4.9 & 1.97 \\
& & Identified but not fixed & 1.55 & 1.27 \\
& & Wrong attempt & 0.45 & 0.99 \\
Third-year students & \multirow{2}{*}{20} & Identified \& fixed & 3.5 & 1.79 \\
& & Identified but not fixed & 1.25 & 1.37 \\
& & Wrong attempt & 0.15 & 0.36 \\
Second-year students & \multirow{2}{*}{20} & Identified \& fixed & 3.05 & 2.18 \\
& & Identified but not fixed & 0.95 & 0.94 \\
& & Wrong attempt & 0.35 & 0.48 \\
\hline
\end{tabular}


TABLE 3. One-way ANOVA analysis of students' gain scores in spelling

\begin{tabular}{llcccc}
\hline Error correction attempts & & $\mathrm{df}$ & Mean Square & $\mathrm{F}$ & $\mathrm{p}$ \\
\hline Identified \& fixed & Between Groups & 2 & 18.61 & 4.70 & .012 \\
& Within Groups & 57 & 3.96 & & \\
& Total & 59 & & & \\
Identified but not fixed & Between Groups & 2 & 1.8 & 1.22 & .30 \\
& Within Groups & 57 & 1.46 & & \\
Wrong attempt & Total & 59 & & & \\
& Between Groups & 2 & 0.46 & 1.02 & .36 \\
& Within Groups & 57 & 0.45 & & \\
& Total & 59 & & & \\
\hline
\end{tabular}

The results of students' performance on grammar correction, however, followed a different direction. As illustrated in Tables 4 and 5, the means of three grammar correction attempts varied slightly between the groups, with the second-year students having a marginal gain of approximately one score higher than their counterparts to identify and fix their grammar errors specifically. However, the differences were not significant at the $\mathrm{p}<.05$ level for all attempts.

TABLE 4. Descriptive analysis of students' gain scores in grammar

\begin{tabular}{lllll}
\hline Treatments & $\mathrm{n}$ & Error correction attempts & $\mathrm{M}$ & SD \\
\hline Fourth-year students & \multirow{2}{*}{20} & Identified \& fixed & 9.75 & 2.33 \\
& & Identified but not fixed & 2.25 & 1.25 \\
& & Wrong attempt & 1.55 & 1.35 \\
Third-year students & \multirow{2}{*}{20} & Identified \& fixed & 10.3 & 1.41 \\
& & Identified but not fixed & 1.8 & 1.32 \\
& & Wrong attempt & 0.8 & 0.76 \\
Second-year students & \multirow{2}{*}{20} & Identified \& fixed & 11.2 & 1.98 \\
& & Identified but not fixed & 1.7 & 1.08 \\
& & Wrong attempt & 1.4 & 0.99 \\
\hline
\end{tabular}

TABLE 5. One-way ANOVA analysis of students' gain scores in grammar

\begin{tabular}{llcccc}
\hline Error correction attempts & & $\mathrm{df}$ & Mean Square & $\mathrm{F}$ & $\mathrm{p}$ \\
\hline Identified \& fixed & Between Groups & 2 & 10.71 & 2.81 & .068 \\
& Within Groups & 57 & 3.80 & & \\
Identified but not fixed & Total & 59 & & & \\
& Between Groups & 2 & 1.71 & & .32 \\
& Within Groups & 57 & 1.49 & & \\
Wrong attempt & Total & 59 & & & .071 \\
& Between Groups & 2 & 3.15 & 2.76 & \\
\hline
\end{tabular}

Similar to students' performance on correcting spelling errors, the results of students' attempts on punctuation displayed in Tables 6 and 7 reveal significant differences between means at the first attempt only (identified \& fixed), with fourth-year students displaying a stronger ability to identify and fix punctuation errors in their essays $[\mathrm{F}(2,57)=4.01, \mathrm{p}=.023]$. These differences, however, were not significant for the two other attempts (identified but not fixed $[\mathrm{F}(2,57)=2.82, \mathrm{p}=.067]$ and wrong attempt $[\mathrm{F}(2,57)=1.62, \mathrm{p}=.205])$.

TABLE 6. Descriptive analysis of students' gain scores in punctuation

\begin{tabular}{lllll}
\hline Treatments & $\mathrm{n}$ & Error correction attempts & $\mathrm{M}$ & $\mathrm{SD}$ \\
\hline Fourth-year students & \multirow{2}{*}{20} & Identified \& fixed & 4.65 & 2.90 \\
& & Identified but not fixed & 0.35 & 0.58 \\
& & Wrong attempt & 0.8 & 1.10 \\
\hline
\end{tabular}




\begin{tabular}{|c|c|c|c|c|}
\hline \multirow{3}{*}{ Third-year students } & & Identified \& fixed & 3.05 & 1.87 \\
\hline & 20 & Identified but not fixed & 0.25 & 0.44 \\
\hline & & Wrong attempt & 0.3 & 0.65 \\
\hline \multirow[t]{3}{*}{ Second-year students } & & Identified \& fixed & 2.9 & 1.44 \\
\hline & 20 & Identified but not fixed & 0.7 & 0.80 \\
\hline & & Wrong attempt & 0.75 & 1.06 \\
\hline
\end{tabular}

TABLE 7. One-way ANOVA analysis of students' gain scores in punctuation

\begin{tabular}{llcccc}
\hline Error correction attempts & & $\mathrm{df}$ & Mean Square & $\mathrm{F}$ & $\mathrm{p}$ \\
\hline Identified \& fixed & Between Groups & 2 & 18.81 & 4.01 & .023 \\
& Within Groups & 57 & 4.68 & & \\
Identified but not fixed & Total & 59 & & & .067 \\
& Between Groups & 2 & 1.11 & 2.82 & \\
Wrong attempt & Within Groups & 57 & 0.39 & & .205 \\
& Total & 59 & & & \\
& Between Groups & 2 & 1.51 & & \\
\hline
\end{tabular}

In response to the second research question, qualitative analysis of the students' interview data revealed ten common strategies and resources they consulted, mainly beyond the classroom, to tackle language-related errors in their writing. Although students indicated that most disciplinary faculty emphasised linguistically error-free texts and some reduced marks for the poor language of their writing, only two teachers provided feedback on their errors by underlining severe linguistic errors in their exam papers. Thus, the faculty feedback was not considered as a common strategy. However, it appears that the faculty expectation of writing linguistically correct texts motivated some students to take this aspect of their writing seriously.

Some teachers reduce marks for bad grammar, but they do not help. We can only see our papers in the class, but I know if I want more marks, I have to be good at my grammar too. So, I always read, take notes and then edit my notes to improve my grammar. (Fourth-year student)

TABLE 8. Frequency of the common strategies or resources used

\begin{tabular}{|c|c|c|c|c|c|}
\hline \# & Strategy/Resource & $\begin{array}{l}\text { 4th } \\
\text { year }\end{array}$ & $\begin{array}{l}3 \mathrm{rd} \\
\text { year }\end{array}$ & $\begin{array}{l}2 \text { nd } \\
\text { year }\end{array}$ & Tota \\
\hline 1 & Reading (e.g., course books, newspapers and fiction) & 14 & 12 & 8 & 34 \\
\hline 2 & Typing (e.g., assignments and projects) & 14 & 10 & 9 & 33 \\
\hline 3 & Watching videos (e.g., movies and YouTube lessons) & 8 & 10 & 12 & 30 \\
\hline 4 & Speaking \& listening (e.g., talking with or listening to others) & 11 & 9 & 6 & 26 \\
\hline 5 & Googling (online search) & 5 & 6 & 8 & 19 \\
\hline 6 & Peer-correction (or asking for help) & 3 & 5 & 7 & 15 \\
\hline 7 & Dictionaries & 4 & 5 & 5 & 14 \\
\hline 8 & Language learning applications & 4 & 4 & 4 & 12 \\
\hline 9 & Teaching others & 3 & 4 & 5 & 12 \\
\hline 10 & Grammar books & 4 & 2 & 2 & 8 \\
\hline \multicolumn{2}{|c|}{ Total } & 70 & 67 & 66 & 203 \\
\hline
\end{tabular}

As expected, reading course books and reading for pleasure were the most commonly reported strategy that helped students improve their written linguistic accuracy. Over half of the students $(57 \%)$ reported reading as the context for noticing the use of grammar, amongst other aspects of linguistic accuracy.

Reading is the key. When I read, I discover how I was writing something incorrectly for a long time. I am reading the "Mean Girls" now and when I read, I take notes to improve my grammar and vocabulary.

(Second-year student) 
Typing assignments and projects was another beneficial practice aiding students $(55 \%)$ in identifying and mainly correcting surface-level linguistic errors in their texts. The grammar and spelling checker options in Microsoft Word and other word-processing applications were acknowledged as valuable tools for highlighting spelling, grammar, and punctuation errors and suggesting corrections while students drafted and redrafted their writing.

\section{I am using an application to find and correct my writing errors. Typing also helps me become aware of my errors. They both help me impress my teachers and get better marks.}

As the third most frequent strategy, half of the students indicated that watching movies raised their awareness of how grammar is used in context. They also mentioned that on special occasions watching YouTube lessons on grammar helped them improve their knowledge of grammar when they encountered a problem in a specific area such as tenses and prepositions.

I remember I had a problem with "have/has been". Then I watched a video on YouTube and learned how to use it.

(Third-year student)

Moreover, students believed that similar to their experience with reading; they had a chance to develop their general English ability and notice how other people use the correct language when watching movies. Interestingly, second-year students $(60 \%)$ were in favour of this strategy and supported it more strongly than the third-year (50\%) and fourth-year (40) students.

Movies open our eyes to many things. I am the type of person who focuses on the language actors use, their pronunciation of the new words and their use of structures. My friends think I watch a lot of movies, but I just love self-study. (Fourth-year student)

Less than half of the students (40\%) also referred to speaking and listening activities in developing their linguistic knowledge.

When other students talk in the class, I can understand my mistakes. For example, I learned when to add 'ed' and when not add 'ed' to verbs. I also learned many new words in this way.

(Second-year student)

Searching (Googling) linguistic problems online and drawing on peer correction or asking for help, especially during pair and group activities, were the following two frequent strategies supported mainly by less senior students. However, although most of the students accessed online resources, only over $30 \%$ relied on such resources to deal with form-based issues in their writing.

When I wanted to know how to use something, I Google it. During drafting my assignments, I keep Googling my problems. When my friends ask something, I watch videos on YouTube or Google them to learn how to help them.

More or less, the same number of students reported using dictionaries or language learning applications, teaching others, and consulting grammar books as other helpful but less frequent strategies to improve their linguistic accuracy.

In the past I had problems with spelling; now when I write I go back and read it for two to three times to edit it. I use dictionaries, applications or online programmes for this purpose.

Students' strategic behaviour or use of such learning resources to develop their written linguistic accuracy appeared to be, however, mediated by contextual affordances such as academic and professional goals or plans. For example, most students $(66 \%)$ reported setting 
up plans to improve their general English, viewing grammar as a component of general language proficiency. However, only around a quarter of students $(21 \%)$ specifically mentioned grammar as part of their plan, as they thought they would need it for their future field of study or career. Those majoring in psychology and business, for example, claimed that they would not need grammar; instead, they believed they would need to read more and invest in developing their oral communication skills to succeed in their future studies or profession. On the other hand, students who decided to pursue a job in education (e.g., teaching English) were planning to take grammar classes, buy grammar books and attempt online grammar quizzes to develop their knowledge of grammar.

\footnotetext{
When I graduate, I want to spend more time on my grammar. I will take a course in British Council, if possible, because I want to take IELTS and apply for an MA programme in the UK. I am going to work as a teacher and I need it.

(Fourth-year student)
}

On the last interview question, all students indicated that they would write their essays differently had they been given another chance.

If I have a chance, I will write it differently. I think I repeated many sentences. I will use new words, new ideas, and new structures. This looks like a kid's writing. I never write like this now.

(Fourth-year student)

Overall, students' responses to the interview questions highlighted the role alternative sources of learning and feedback played in helping them address linguistic errors in their writing. Such data also indicated that faculty teachers' expectations along with contextual affordances guided and directed students' strategic behaviour or their use of specific mediational means to deal with language-related errors in their written work.

\section{DISCUSSION}

This study sought to explore EFL university students' written linguistic accuracy development in disciplinary contexts. Although it singled out linguistic accuracy, amongst other aspects of L2 writing development, and examined its progress over time, the findings resonate with those of the previous research (e.g., Hyland, 2013a; Knoch et al., 2014; Knoch et al., 2015; Storch \& Hill, 2008) that suggested disciplinary acculturation would be less likely to affect all aspects of students' writing development equally. The results revealed that students could significantly identify and fix only spelling and punctuation errors, as surface-level issues that can be easily noticed and corrected, rather than grammatical errors, which are more complex and vary in range and severity.

Several factors could explain slow development or lack of significant progress in grammar in this context. First, an inadequate emphasis is placed on teaching writing at schools and pre-degree programmes at higher education (Al-Mahrooqi \& Denman, 2018; Naghdipour, 2021). Students, therefore, perhaps similar to students in other EFL contexts (Shen et al., 2020), are not familiar with effective editing strategies to spot and correct language-related errors in their writing. Second, although grammar is accentuated across students' pre-secondary and predegree education, traditional approaches are generally advocated to teach it (Al-Mahrooqi \& Denman, 2018; Naghdipour, 2021). This deprives students of being exposed to learning grammar in the context of other skills, mainly speaking and writing, which can help them notice gaps in their interlanguage through activities that entail comprehensible output (Swain, 2005). In other words, an absence of proper context with adequate scaffolding to enhance "noticing" of how language works in context (Hyland, 2007; Schmidt, 2001) is one of the missing loops 
in early levels of education in this context where grammar is taught as a set of rules reinforced by using mechanical drills and exercises (Al-Mahrooqi \& Denman, 2018).

Last but not least, developing writing skills, similar to any other skill, requires repetition to reach automatisation through extensive practice and constant feedback (DeKeyser, 2007). However, as the results indicated, such well-orchestrated efforts, like strategy instruction and training, to create a sustainable environment for students to keep working on their linguistic accuracy were also missing in this context. In other words, except for few cases where disciplinary faculty emphasised the importance of linguistic accuracy through, for example, underlining some selected errors, students were left on their own to attend to linguistic errors in their writing.

Despite receiving insufficient support from faculty teachers, students drew on many resources and strategies or alternative feedback techniques (e.g., Abadikhah \& Yasami, 2014; Ferris, 2006; Mawlawi Diab, 2016) to deal with linguistic errors in their writing. Motivated mainly through personal goals, career plans, and constant and unlimited access to a vast repertoire of online learning resources, many students took the initiative to proofread or edit their written work to better prepare for exams or impress their teachers for better marks. Although there exists a consensus in support of written corrective feedback interventions on students' linguistic accuracy improvement in writing (e.g., Ferris et al., 2013; Shintani et al., 2013; Van Beuningen et al., 2012), faculty might have been discouraged to focus on linguistic errors due to low institutional expectations and the existence of practical constraints such as heavy teaching load or lack of training (Naghdipour, 2016). They might also view feedback on language-related issues beyond the remit of their responsibility.

Thus, it appears that disciplinary acculturation impacted students' attitudes towards what should be prioritised, the content and expertise or language. Hyland (2013a) also suggests that language learning programmes and disciplinary programmes follow different ideologies and expectations. This is best reflected in the fact that second-year students outperformed the other two groups in terms of their gain scores on grammar, used more peer feedback and sought more technology-driven tools for feedback and fixing their errors. Such a difference could be attributed to these students' least experience with disciplinary content and more attachment to language learning skills as they usually take skill-based courses in the first two years of their studies.

\section{CONCLUSION}

Overall, while the findings of this study could trigger further discussion on L2 linguistic development in writing, it is difficult to generalise them to other EFL contexts primarily because the collected data came from a small sample size. However, the study offers several pedagogical implications for the contexts where English as the medium of instruction policy has been adopted to prepare students for better academic and professional achievements. The findings imply that equipping students with error detection and correction skills at lower levels of education may give them the proper toolkit to deal with linguistic issues later in their writing in academic settings. Similarly, disciplinary faculty should advocate more practical approaches to assisting students in editing their written work, rather than sharing rubrics and marking schemes. Even when time is in short supply or administrative duties deprive them of this opportunity, faculty may seek out ways to familiarise students with alternative feedback strategies and resources to make better compromises between knowledge of the language and disciplinary knowledge whenever and wherever necessary (Hyland, 2013a; Wingate \& Tribble, 2012). To raise students' awareness of such strategies, teachers can, for example, encourage them to visit writing centres, learning clubs and labs and engage in formative assessment 
techniques such as self- and peer-editing activities (Abadikhah \& Yasami, 2014; Mawlawi Diab, 2016; Naghdipour, 2021). Providing whole-class feedback on the most common errors through designing short mini-lessons of 15 to 20 minutes (Mansourizadeh \& Abdullah, 2014; Nusrat et al., 2019) after each major student submission could be another initiative to help students minimise language-related errors in their writing. In addition to contributing to the quality of their written work, this could raise students' awareness of the importance of producing linguistically correct texts in academic contexts.

There are, however, limitations that future studies need to address while investigating undergraduates' written linguistic accuracy development in disciplinary contexts. In particular, the focus of this study was limited to linguistic accuracy, among other aspects of writing development. If writing skills were examined as a holistic ability, a clearer picture of students' experiences with writing in disciplinary contexts would be obtained. In addition, the study required students to edit or proofread a text they produced before to control the task type, assuming that this could better showcase students' written accuracy development. However, if students had a chance to rewrite their essays and provide the newly learned content and ideas, a more realistic profile of their weaknesses and strengths in writing would be depicted. Finally, students in different groups might have had individual differences in attention, motivation, goals and beliefs that could affect the use of various resources and strategies to address linguistic errors in their writing. Controlling such variables in future research could better explain students' strategic behaviour concerning their use of alternative sources of learning and feedback to minimise linguistic errors in their writing. Despite these limitations, the insights gained from this study suggest that students would encounter serious challenges dealing with linguistic issues in their written work in degree programmes and the workplace unless they are provided with opportunities to improve their written linguistic accuracy in disciplinary contexts.

\section{REFERENCES}

Abadikhah, S, \& Yasami, F. (2014). Comparison of the effects of peer- versus self-editing on linguistic accuracy of Iranian EFL students. 3L: The Southeast Asian Journal of English Language Studies, 20(3), 113-124.

Al-Mahrooqi, R., \& Denman, C. (2018). English education in Oman: Current scenarios and future trajectories. Springer.

Bawarshi, A. S., \& Reiff, M. J. (2010). Genre: An introduction to history, theory, research, and pedagogy. Parlor Press and The WAC Clearinghouse.

Bazerman, C. (2009). Genre and cognitive development. In C. Bazerman, A. Bonini, \& D. Figueiredo (eds.), Genre in a Changing World (pp. 283-298). Parlor Press.

Bitchener, J., \& Knoch, U. (2010). Raising the linguistic accuracy level of advanced L2 writers with written corrective feedback. Journal of Second Language Writing, 19, 207-217.

Boggs, J. (2019). Effects of teacher-scaffolded and self-scaffolded corrective feedback compared to direct corrective feedback on grammatical accuracy in English L2 writing. Journal of Second Language Writing, 46, 1-13.

Bruton, A. (2009). Improving accuracy is not the only reason for writing, and even if it were ... . System, 37, 600613.

Chen, S., Nassaji, H., \& Liu, Q. (2016). EFL learners' perceptions and preferences of written corrective feedback: A case study of university students from mainland China. Asian-Pacific Journal of Second and Foreign Language Education, 1(5), 1-17.

DeKeyser, R. (2007). Skill acquisition theory. In B. VanPatten \& J. Williams (Eds.), Theories in second language acquisition (pp. 97-113). Lawrence Erlbaum.

Ellis, R. (2005). Principles of instructed language learning. System, 33(2), 209-224.

Evans, N. W., Hartshorn, K. J., McCollum, R. M., \& Wolfersberger, M. (2010). Contextualising corrective feedback in L2 writing pedagogy. Language Teaching Research, 14(4), 445-463.

Ferris, D. R. (1999). The case of grammar correction in L2 writing classes: a response to Truscott (1996). Journal of Second Language Writing, 8(1), 1-11. 
Ferris, D. R. (2006). Does error feedback help student writers? New evidence on the short- and long-term effects of written error correction. In K. Hyland \& F. Hyland (Eds.), Feedback in second language writing: Contexts and issues (pp. 81-104). Cambridge University Press.

Ferris, D. R. (2010). Second language writing research and written corrective feedback in SLA: Intersections and practical applications. Studies in Second Language Acquisition, 32, 181-201.

Ferris, D. R., \& Hedgcock, J. S. (2013). Teaching ESL composition: Purpose, process, and practice (3rd ed.). Routledge.

Ferris, D. R., Liu, H., Sinha, A., \& Senna, M. (2013). Written corrective feedback for individual L2 writers. Journal of Second Language Writing, 22(3), 307-329.

Harklau, L. (2002). The role of writing in classroom second language acquisition. Journal of Second Language Writing, 11, 329-350.

Hyland, K. (2007). Genre pedagogy: Language, literacy and L2 writing instruction. Journal of Second Language Writing, 16(3), 148-164.

Hyland, K. (2013a). Faculty feedback: Perceptions and practices in L2 disciplinary writing. Journal of Second Language Writing, 22(3), 240-253.

Hyland, K. (2013b). Writing in the university: Education, knowledge and reputation. Language Teaching, 46, 5370 .

Hyland, K., \& Hyland, F. (2006). Feedback on second language students' writing. Language Teaching, 39(2), 83101.

Knoch, U., Rouhshad, A., \& Storch, N. (2014). Does the writing of undergraduate ESL students develop after one year of study in an English-medium university? Assessing Writing, 21, 1-17.

Knoch, U., Rouhshad, A., Oon, S. P., \& Storch, N. (2015). What happens to ESL students' writing after three years of study at an English medium university? Journal of Second Language Writing, 28, 39-52.

Lee, I. (2009). Ten mismatches between teachers' beliefs and written feedback practice. ELT Journal, 63(1), 1322.

Lee, Y.-J. (2020). The long-term effect of automated writing evaluation feedback on writing development. English Teaching, 75(1), 67-92.

Manchón, R. M. (2011). Writing to learn the language: Issues in theory and research. In R. M. Manchón (Ed.), Learning-to-write and writing-to-learn in an additional language (pp. 61-82). John Benjamins.

Mansourizadeh, K. \& Abdullah, K.I. (2014). The Effects of Oral and Written Meta-Linguistic Feedback on ESL Students Writing. 3L: Language, Linguistics,Literature ${ }^{\circledR}, 20(2), 117-126$.

Mawlawi Diab, N. (2016). A comparison of peer, teacher and self-feedback on the reduction of language errors in student essays. System, 57, 55-65.

Naghdipour, B. (2016). English writing instruction in Iran: Implications for second language writing curriculum and pedagogy. Journal of Second Language Writing, 32, 81-87.

Naghdipour, B. (2021). English writing pedagogy at the crossroads: The case of Oman. Journal of Second Language Writing, 52, 100815.

Naghdipour, B., \& Koç, S. (2015). The evaluation of a teaching intervention in Iranian EFL writing. The AsiaPacific Education Researcher, 24(2), 389-398.

Nusrat, A. Ashraf, F. \& Combes, M. F. N. (2019). Effect of Direct and Indirect Teacher Feedback on Accuracy of English Writing: A Quasi-Experimental Study among Pakistani Undergraduate Students. 3L: Language, Linguistics, Literature ${ }^{\circledR}$ 25(4), 84-98.

Oppenheimer, D., Zaromb, F., Pomerantz, J. R., Williams, J. C., \& Park, Y. S. (2017). Improvement of writing skills during college: A multi-year cross-sectional and longitudinal study of undergraduate writing performance. Assessing Writing, 32, 12-27.

Pienemann, M. (1989) Is language teachable? Psycholinguistic experiments and hypotheses. Applied Linguistics, $10(1), 52-76$.

Polio, C. G. (1997). Measures of linguistic accuracy in second language writing research. Language Learning, 47, 101-143.

Polio, C., \& Shea, M. C. (2014). An investigation into current measures of linguistic accuracy in second language writing research. Journal of Second Language writing, 26, 10-27.

Rollinson, P. (2005). Using peer feedback in the ESL writing class. ELT Journal, 59(1), 23-30.

Schmidt, R. (2001). Attention. In P. Robinson (Ed.), Cognition and second language instruction (pp. 3-32). Cambridge University Press.

Shaw, P., \& Liu, E. T. (1998). What develops in the development of second-language writing? Applied Linguistics, 19, 225-254.

Shen, B., Bai, B. \& Xue, W. (2020). The effects of peer assessment on learner autonomy: An empirical study in a Chinese college English writing class. Studies in Educational Evaluation, 64, 1-10.

Shintani, N., Ellis, R., \& Suzuki, W. (2013). Effects of written corrective feedback and revision on learners' accuracy in using two English grammatical structures. Language Learning, 64, 103-121. 
Storch, N. (2009). The impact of studying in a second language (L2) medium university on the development of L2 writing. Journal of Second Language Writing, 18, 103-118.

Storch, N. (2010). Critical Feedback on Written Corrective Feedback Research. International Journal of English Studies, 10(2), 29-46.

Storch, N., \& Hill, K. (2008). What happens to international students' English after one semester at university? Australian Review of Applied Linguistics, 31(1), 1-17.

Swain, M. (2005). The output hypothesis: Theory and research. In E. Hinkel (Ed.), Handbook of research in second language teaching and learning (pp. 471-483). Lawrence Erlbaum Associates.

Van Beuningen, C. G., De Jong, N., \& Kuiken, F. (2012). Evidence on the effectiveness of comprehensive error correction in second language writing. Language Learning, 62(1), 1-41.

Waller, L., \& Papi, M. (2017). Motivation and feedback: How implicit theories of intelligence predict L2 writers' motivation and feedback orientation. Journal of Second Language Writing, 35, 54-65.

Wingate, U., \& Tribble, C. (2012) The best of both worlds? Towards an English for Academic Purposes/Academic Literacies writing pedagogy. Studies in Higher Education, 37(4), 481-495. 


\section{APPENDIX}

\section{INTERVIEW PROTOCOL}

1. How do you evaluate your writing proficiency? If satisfied, how have you improved it? Which area of your writing (e.g., grammar, organisation, content) has improved the most at university? Which one remained the same? Why?

2. What is the importance of spelling, grammar, and punctuation in writing? How do you evaluate your knowledge in these three areas? If satisfied, how have you improved each? What sources and resources, if any, have you used? Which one was the most or least effective?

3. How often do you write? What types of writing tasks and assignments have you been given? What type of feedback, if any, have you received on your work? Have you received feedback on spelling, grammar, and punctuation? If so, how did you respond to the received feedback?

4. How do you know if you are using correct spelling, grammar, and punctuation when you write? If not sure, how do you correct your errors in these three areas?

5. Do you have any plans to work on your spelling, grammar, and punctuation in the future?

6. How do you feel reading your essay after some time? If given another chance, do you think you would write the same essay? 